International Research Journal of Engineering, IT \& Scientific Research
Available online at https://sloap.org/journals/index.php/irjeis/
Vol. 5 No. 6, November 2019, pages: $25 \sim 32$
ISSN: 2454-2261
https://doi.org/10.21744/irjeis.v5n6.806

\title{
Learning Problems: Pedagogical Intervention
}

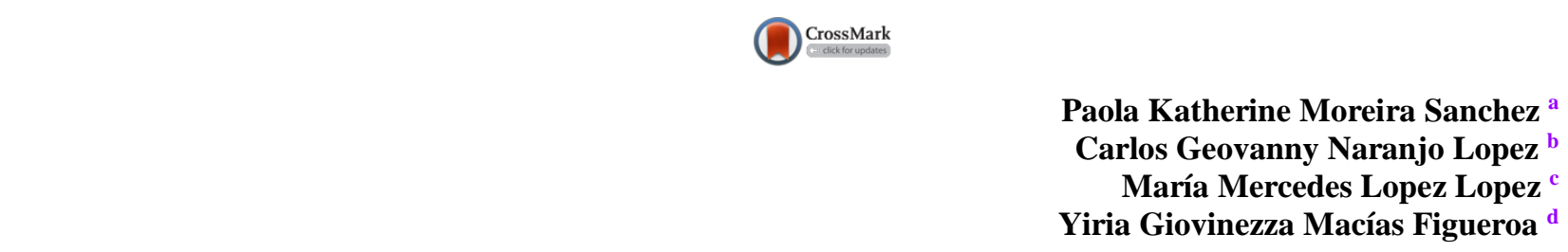

Article history:

Received: 09 February 2019

Accepted: 30 September 2019

Published: 21 November 2019

\section{Keywords: \\ acquisition; \\ disorder; \\ dyslexia; \\ learning; \\ pedagogic;}

\begin{abstract}
Learning problems Pedagogical intervention is necessary studies in the educational field, in which all teachers must have adequately trained. The general objective of the present investigation was to know the difficulties that the students have in the process of knowledge acquisition, for it a bibliographical revision on disorders and symptoms of learning has carried out. Types of dyslexia; cognitive stages in the development of the child; In addition, the methodology applied was qualitative and descriptive, which allowed understanding and interpreting situations in the development of information about learning problems and pedagogical intervention. Among the methods used was the heuristic, which led to the discovery of problems in student learning; Field research has also carried out. The analysis and interpretation of results gave way to establish strategies in the use of pedagogical tools that improve the difficulty of learning.
\end{abstract}

2454-2261 ${ }^{\odot}$ Copyright 2019. The Author. This is an open-access article under the CC BY-SA license (https://creativecommons.org/licenses/by-sa/4.0/) All rights reserved.

\section{Author correspondence:}

Paola Katherine Moreira Sanchez,

Master's Degree in Education Innovation, Pontificia Universidad Católica del Ecuador.

Email address: paomork_21r@yahoo.com

\section{Introduction}

Dyslexia is a disorder that affects mainly in reading and writing, it is a problem that is found in the brain area, however, it is not a disease, it is a disorder in the specific information procedure, it does not interfere in the ability to think, at the time of reading, is not a problem of intelligence, so it is necessary to be diagnosed in time, to be able to carry out pedagogical activities that help overcome these difficulties in learning.

It is necessary to know the learning problems, through the experiences lived with professionals and students, who were the source of information for the study where they developed a series of strategies based on aptitude and the

\footnotetext{
a Pontificia Universidad Católica del Ecuador

${ }^{\mathrm{b}}$ Universidad Laica Eloy Alfaro de Manabí, Ecuador

${ }^{c}$ Pontificia Universidad Católica del Ecuador

${ }^{\mathrm{d}}$ Pontificia Universidad Católica del Ecuador
} 
interest of the students, to achieve learning as a goal of the research, allows to know the difficulties that the students have in the learning. The sources of information provided the solution of problems in the learning and pedagogical intervention; the teacher must understand the learner in the different forms of learning, so he needs to establish pedagogical tools to measure the cognitive level and the learning process, using teaching strategies for the transformation of educational models for better performance and balance in teaching. Currently, in Ecuador, different studies are being carried out on the application of neuroscience in pedagogy in support of the disorders that affect students (Meza et al., 2019; Chávez et al., 2019).

\section{Materials and Methods}

In the methodological process of this research, was qualitative and descriptive, where it was described and understood to interpret situation about learning problems and pedagogical intervention, the technique of field observation was used, in addition to the heuristic method that entailed to the knowledge of learning problems in students; Field and bibliographical research was also conducted by reference of authors of theses, articles, and other electronic sources. The analysis and interpretation of results gave way to establish strategies such as the use of pedagogical tools to improve the difficulty of learning, for the elaboration of the graphic organizer the MindMaster application has used.

\section{Results and Discussions}

\subsection{Disorders Learning}

Disorders occur because of the way in which the brain is incorporated and information is processed; so there are people who learn in different ways, so it is necessary to investigate how learning can be improved, consulting with educational specialists or psychologists, who have knowledge about the subject and can help to reduce the disorders caused in the life of the student.

Learning disorders (AD) is defined as a difficulty in an academic area presented by each child at the time of learning, however, it has its own rhythm of learning, it is said that the higher the cognitive capacity, the better it will be able to face a possible difficulty in the learning process, can develop strategies that help overcome problems generated by the disorder.

Problems in learning, may have a genetic basis, which is transmitted from generation to generation in the genes and some are inherited by the traits of parents and grandparents, maybe the closest to the causes of learning is given by relatives they suffer from the learning disorder.

Genetics has a necessary role in the system of teaching and learning, it is common in these difficulties to be repeated from generation to generation due to the fact that several genes are involved; Some study of the genetics of blood groups goes from the concrete to the abstract and sometimes becomes complex for the student (Harstad, 2019; Yusuf et al., 2016).

When this learning disorder is transmitted by the family in a predictable way, or by a close relative with difficulties it could increase the likelihood that another family member will have them too. The disorder of dyslexia comes from genetics, it can be explained that it would be difficult to determine the causes that determine the learning difficulties.

Within the learning difficulties is common to associate behavior and behavior that are terms used to describe, the actions that a student has when interacting with the environment (Ramírez, 2015), states that not every type of educational intervention requires the same level of technical competence: The teacher must understand the student's learning rate according to the interest, ability, and ability of each one of them. A father educates; a subject can self educate himself; There is an informal education process. In all these processes educational results are achieved, it is necessary to apply a pedagogical technique that can control and improve the learning process.

Throughout the educational process, the child depends on external stimuli, that is, on their own attitude, abilities, and skills, this implies a series of guides or positions on which the acts and actions in which living beings interact with are based. the middle. 


\subsection{Symptoms of learning disorders}

The most common symptoms of learning disorders are the following.

Learning disorders, affect the child the skill and ability to develop in an academic area such as reading, oral expression, and mathematical operations, you can see the ability and success in the specific academic area according to age. When the difficulty of a child is severe, it is noticeable when it comes to academic success or normal activities in daily life.

The learning difficulties (DEA), can be known through research and Delos, which allows us to analyze and identify the causes of poor performance and school failure.

Dyslexia manifests itself in the difficulties in decoding and in each phone book that has assigned in a graphic representation. The child has trouble to apply the grammar rules:

In dyscalculia, people are intelligent, have difficulties with numbers, this disorder, an inability to perform arithmetic operations and numerical confusion (Cobo, 2011; Delgado et al., 2019). Raises that a child with dyslexia, has difficulties in learning, this can develop other skills that solve simple problems; Sometimes, when the inconveniences are complex, they tend to be difficult; then it is necessary to create tools and signs that help during the learning process to guarantee school performance.

Dyslexia children have a learning disorder of reading and writing is specific and persistent, cannot assimilate certain subject content, so it cannot reach the meaning through reading, they must put a lot of effort into the tasks, since they tend to get fatigued easily, lose concentration, get distracted and reject this type of activity.

The learning of reading, the child must be prepared to start the process of acquisition of literacy, if a child is not prepared can be thought to have secondary dyslexia, prior to dyslexia without brain involvement. A series of prerequisites can have established to initiate literacy teaching (Tamayo, 2017), for example:

a) Oral language: observe that you have good oral language development.

b) Auditory perception and discrimination: taking into account that they have no significant problems of hearing and discriminating speech sounds and adequate guidance of phonemic awareness.

c) Acquisition of other skills: how are the visuospatial normal, so perceptive that helps to perceive the letters, shape, position and spatial orientation?

d) Graphomotor: adequate level and visomotor coordination.

e) Development of skills and abilities: is the development of skills acquired by the child during the process of knowledge, attention and normal memories, taking into account the emotional maturity and motivation.

Figure 1 shows, the key activities to develop literacy such as oral language, auditory perception, and discrimination, acquisition of other skills and the development of skills, dexterity and adequate graphomotor skills.

Dyslexia problems fundamentally affect language skills, but those affected develop other skills that help to learn. It can have started from a behavioral perspective a dyslexic child, is not one who has not learned or who does not have the ability to read and write. That learned of deficient way, committing errors in his literacy, reason why no longer it would have spoken of these types of disorders; but of children who make mistakes in literacy (Tamayo, 2017; Martinez et al., 2019).

Sanchez, P. K. M., Lopez, C. G. N., Lopez, M. M. L., \& Figueroa, Y. G. M. (2019). Learning problems: pedagogical intervention. International Research Journal of Engineering, IT \& Scientific Research, 5(6), 25-32. 


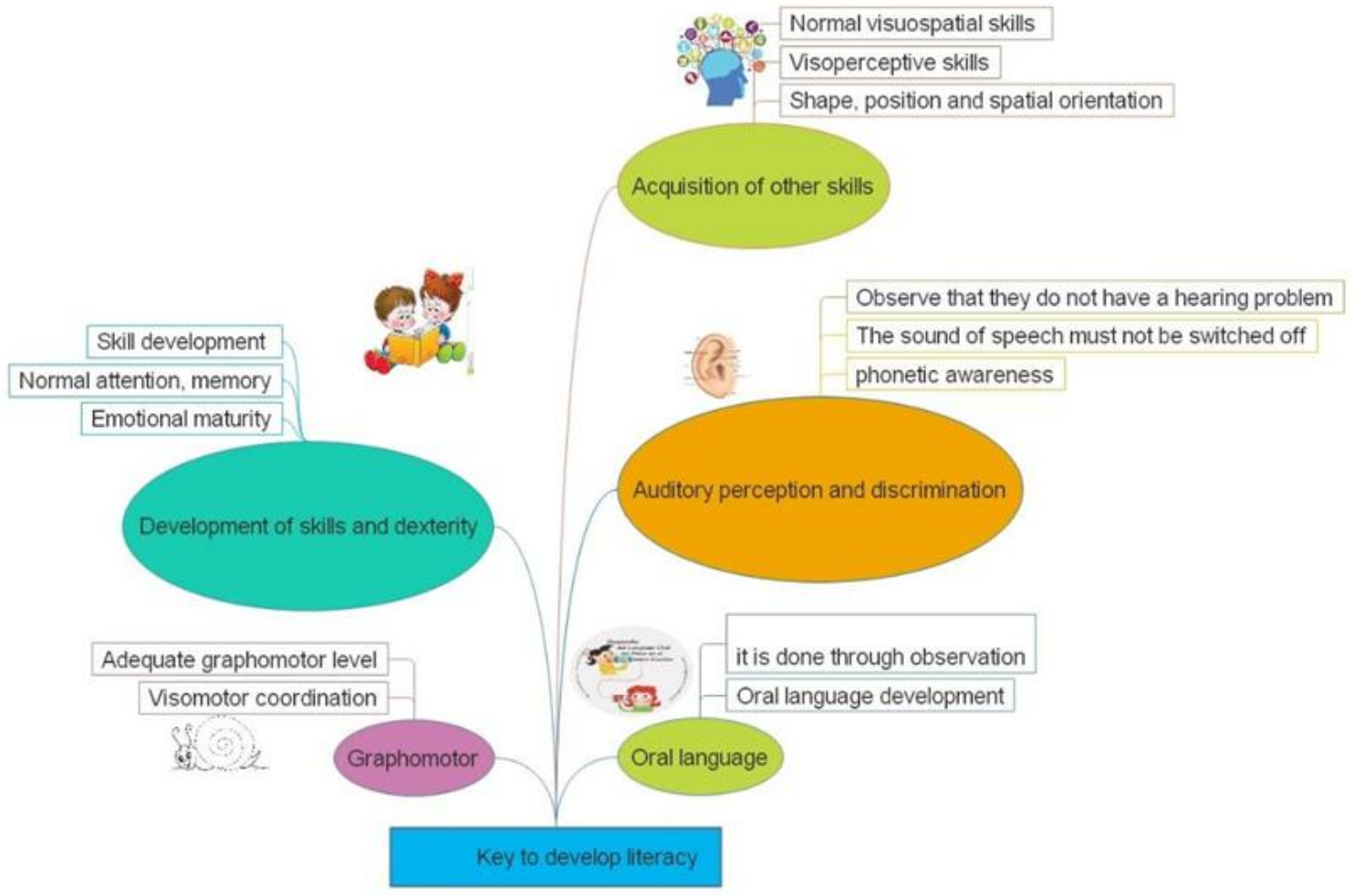

Figure 1. Key to develop literacy

Due to the problems of learning in dyslexic children, it is possible to understand the behavior and behavior of competence in which they are able to carry out the construction of knowledge, with the help of other people.

From the sociocultural theory supports that children develop the construction of learning through social interaction. Authors such as Vygotsky (Rosas, 2016), manifests from the perspective that theorization has importance, on the educational strategies developed by learners, when using tools cultural and didactic, that help interact with the environment; both oral and written language and other symbolic or material tools that affect the learning process and how to act with the world. According to their theory, they identify the cognitive processes, used in the executive functions of the neurosciences are necessary

As resources to master the mental processes are used as psycho-pedagogical instruments during the learning of the graphic organizers inside the classroom, this helps to develop the thoughts and oral language; they also organize the ideas taking into account parameters of application such as images, colors and others. It is necessary to use pedagogical models that help in the teaching and learning process; Constructivism is a way of affirming the knowledge of all things, improve the mental process of the individual, and interact with the environment (Church, 2011).

\subsection{Types of dyslexia related to superficial, audio-phonological, deep syndromes.}

To understand the different types of dyslexia produced by damaging different functionalities such as superficial dyslexia, phonology and deep dyslexia (Alvarez, 2015), refers that superficial dyslexia is a damage to the visual path or direct access to words, which can read perfectly the regular words, through a translation or a grapheme to phoneme. In the case of phonological dyslexia, the damaged route is shown in some people who have difficulty reading those words, unknown or non-existent.

Deep dyslexia is similar to phonological, which has characterized by deterioration, semantic paralexies. Table 1 shows the types of disorders of dyslexia. 
Table 1 shows the types of dyslexia disorders, which the child presents in the learning process, we must consider that dyslexia as a disorder that affects the reading and writing, so it is necessary, that it is diagnosed in time, it is said that one of the disorders that affect learning is superficial dyslexia and phonological.

Table 1

Types of dyslexia

\begin{tabular}{ll}
\hline Types of dyslexia & Dyslexia disorder \\
\hline The superficial dyslexia & $\begin{array}{l}\text { has a problem in the phonological route since this does not allow } \\
\text { them to recognize the word as a whole, they can only read } \\
\text { perfectly the regular words, through a translation or one of } \\
\text { grapheme to phoneme, in the case of }\end{array}$ \\
Phonological dyslexia & $\begin{array}{l}\text { The person shows difficulties in the graphene so they have to use } \\
\text { the lexical route. The reading of familiar words and difficulties in } \\
\text { unknown or non-existent words. }\end{array}$ \\
Deep dyslexia & $\begin{array}{l}\text { It has similarities with phonological, which are characterized by } \\
\text { deterioration, semantic paralexies. }\end{array}$ \\
\hline
\end{tabular}

The different disorders that the child has in the learning process, the teacher must understand that not all show the same difficulty at the time of a reading-writing compression according to the stages.

\subsection{Cognitive stages in the development of the child}

With regard to cognitive stages according to Piaget, described three periods in the development of the child, the first is the stage or sensorimotor period, this takes place in the first years of life, sensorimotor skills, are given through the reflexes. The period of pre-operation and organization of specific, operations are divided into two sub-periods, the first from the 2 to 6 years that appears by the symbolic function is given by imitation and the second operational subperiod from 7 to 11 years, It is given by the ability to mentally operate with knowledge.

The period of formal operations goes from 12 years to adulthood, has the ability to think in an abstract way, the adolescent needs to go through some crises to achieve a definitive identity commitment (Rafael, 2007) when we identify the stages of child's development we could help in the evolution.

The advice that helps children with dyslexia work. Once diagnosed, it can be followed by a series of specific activities, designed to address the areas in which the child has difficulties in the classroom with support at home (Villa, 2015). This author states that one of the activities in which the child reads an interesting topic could enjoy and get and concentrate enjoying more of the reading.

Read aloud, you can detect errors, which allows you to hear the words that have correctly read complex syllables of three or four letters can highlight those syllables you have read well, as you progress and see your improvement your motivation, another activity is through of games like the word soups. It should have emphasized that these activities are not associated with intelligence; the child is able to learn as well as other children.

When there is a case of learning difficulty during the educational development, it is necessary to resort to a pedagogical intervention, which is the set of behaviors involved in the action and the development of the educative tasks with the basis of technical choice, in which the student must have external stimulus, internal for a better development in knowledge.

The pedagogical intervention is carried out indirectly in the individual, this is carried out during the process of social interrelation and the impact is assessed, being able to help recognize how children live and how they adapt according to the stimuli acquired in time and space (Piedra \& Sarmiento, 2015). When a dyslexic child is given a timely pedagogical intervention, it helps him improve the learning process using didactic pedagogy and special pedagogy, which allows monitoring through practical work that improves the individual's performance and selfesteem, it is necessary the intervention of parents and educators for integration into society.

Sanchez, P. K. M., Lopez, C. G. N., Lopez, M. M. L., \& Figueroa, Y. G. M. (2019). Learning problems: pedagogical intervention. International Research Journal of Engineering, IT \& Scientific Research, 5(6), 25-32. 


\section{Conclusion}

Consider that learning problems are not a disease, but a disorder that affects learning in reading and writing in the case of dyslexic children, who are intelligent, but require specialized help for the development of other skills, being necessary there is a pedagogical intervention to improve the learning of these students being timely, you can work with creative activities such as using word searches, mental maps, images, videos, among others.

Conflict of interest statement

The authors declared that they have no competing interests.

Statement of authorship

The authors have a responsibility for the conception and design of the study. The authors have approved the final article.

\section{Acknowledgments}

To colleagues who have supported this research. 


\section{References}

Álvarez, B. (2015). Dyslexia initial detection and intervention program in children's education (undergraduate thesis), Universitat Jaume. repositori.uji.es/xmlui/bitstream/10234/137346/1/TFG_2015_AlvarezPalacioB.pdf

Chávez, E. J. M., Pibaque, W. L. D., Chávez, W. J. M., \& López, M. M. L. (2019). Learning problems on brain disorders. International Research Journal of Engineering, IT \& Scientific Research,5(5), 8-15. https://doi.org/10.21744/irjeis.v5n5.723

Church, A. (2011). Implementation of didactic material for psychopedagogical recovery aimed at children from 5 to 7 years old. (Pre-award thesis) Universidad Politécnica Salesiana, Cuenca-Ecuador. https://dspace.ups.edu.ec/bitstream/123456789/1004/14/UPS-CT002072.pdf

Cobo, B. (2011). Disorders in learning to read, calculate and write. 1(11), 63. https://dialnet.unirioja.es/descarga/articulo/3629119.pdf

Delgado, J. L. D., Bone, Y. I. E. B., Lascano, M. A. G. L., \& España, S. G. G. E. (2019). Dyslexia as learning problem and its pedagogical intervention. International Journal of Health Sciences, 3(3), 1-7. https://doi.org/10.29332/ijhs.v3n3.333

Harstad, E. (2019). Are the learning difficulties in my family genetic? https://www.understood.org/es$\mathrm{mx} /$ family/siblings/multiple-children-learning-issues/are-the-learning-issues-in-my-family-genetic

Martinez, C. J. B., Vasquez, B. S. G., Martinez, M. E. M., \& Gámez, M. R. (2019). Learning problems on educational context for cascol parish. International Journal of Social Sciences and Humanities, 3(2), 145-155. https://doi.org/10.29332/ijssh.v3n2.306

Meza, M. L. R., Moya, M. M. E. \& Sabando, S. A. M. (2019). The Brain as a Fundamental Axis in Learning Process. International research journal of engineering, IT \& scientific research (IRJEIS), ISSN 2454-2261) Vol. 5, No. 4.

Piedra, M., \& Sarmiento, M. (2015). Pedagogical intervention in the first year students of Baccalaureate with dyslexia. (undergraduate thesis), Universidad Politécnica Salesiana, Cuenca- Ecuador. https://dspace.ups.edu.ec/bitstream/123456789/7937/1/UPS-CT004782.pdf

Rafael, A. (2007). Cognitive Development: The Theories of Piaget and Vygotsky. Barcelona: Autonomous University of Barcelona. http://www.paidopsiquiatria.cat/files/Teorias_desarrollo_cognitivo.pdf

Ramírez, C. (2015). Learning problem at school. Ibero-American University Corporation, 13(1), 43-51. https://dialnet.unirioja.es/descarga/articulo/4777933.pdf

Rosas, R. (2016). Icec educational program based on the sociocultural theory of Vygotsky and the interpersonal relationships of the students of the fifth grade of the IE "Simón Bolivar" -Otuzco - la Libertad 2012. (Master's Thesis). National university of Trujillo., http://dspace.unitru.edu.pe/bitstream/handle/UNITRU/3916/TESIS\%20MAESTRIA\%20REYNALDO\%20ROS AS\%20QUISPE.pdf?sequence $=1 \&$ is Allowed $=y$

Tamayo, S. (2017). Dyslexia and difficulties in the acquisition of literacy. Magazine in Redalyc, 21(1), $423-432$. https://www.redalyc.org/pdf/567/56750681021.pdf

Villa, W. (2015). Difficulty of learning-dyslexia that will be carried out in the Republic of Chile school in the seventh year of basic general education (undergraduate thesis), Universidad Politécnica Salesiana. Ecuador basin. https://dspace.ups.edu.ec/bitstream/123456789/12349/1/UPS-CT006448.pdf.

Yusuf, M., Adiputra, N., Sutjana, I. D. P., \& Tirtayasa, K. (2016). The improvement of work posture using rapid upper limb assessment: analysis to decrease subjective disorders of strawberry farmers in Bali. International Research Journal of Engineering, IT \& Scientific Research, 2(9), 1-8.

Sanchez, P. K. M., Lopez, C. G. N., Lopez, M. M. L., \& Figueroa, Y. G. M. (2019). Learning problems: pedagogical intervention. International Research Journal of Engineering, IT \& Scientific Research, 5(6), 25-32. 


\section{Biography of Authors}

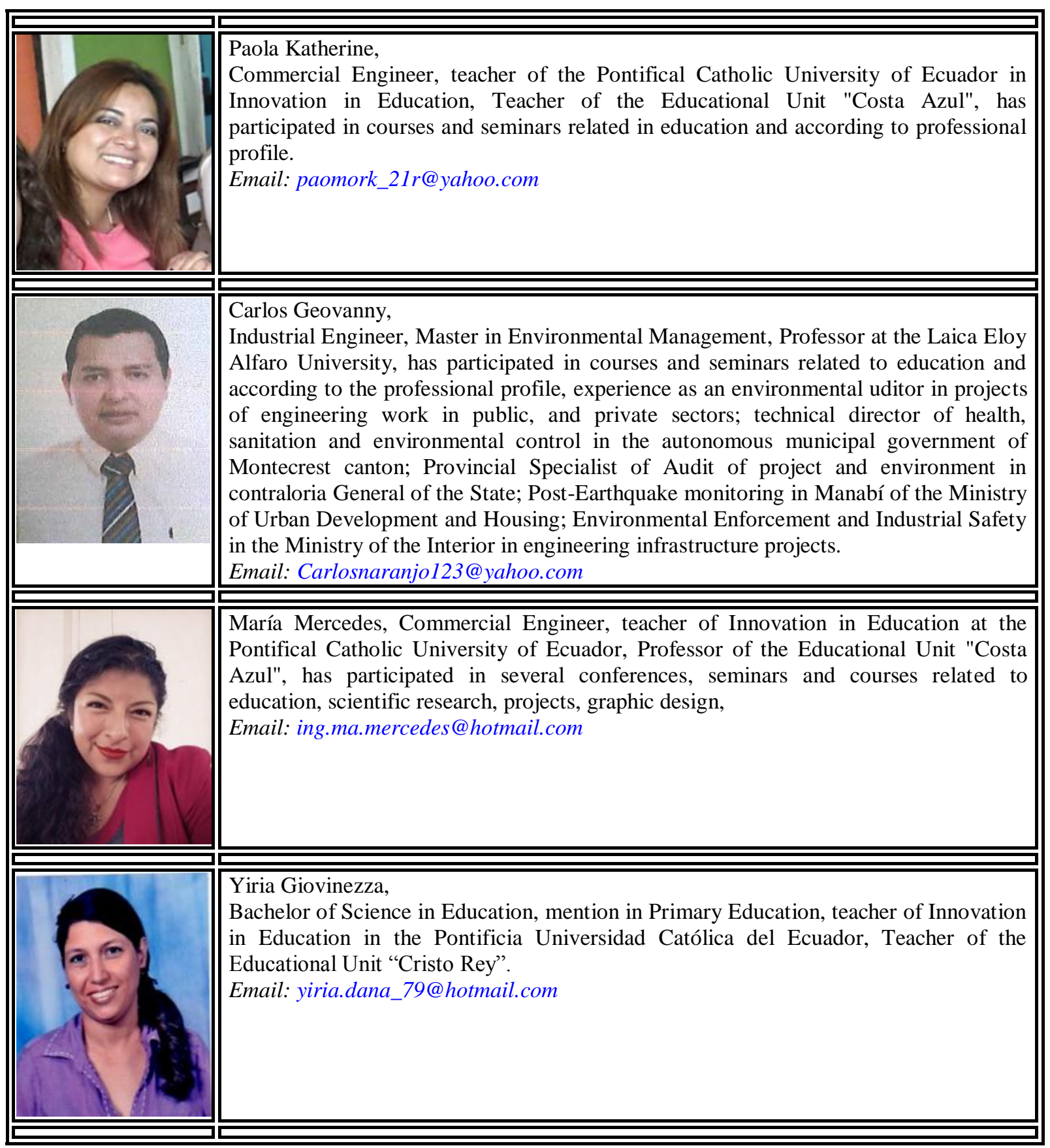

